\title{
KREASI KARAKTER DINOSAURUS SEBAGAI PERWUJUDAN BATIK BAGIAN DARI BUDAYA POPULER
}

\author{
Fatmawati $^{1}$ \\ (Program Studi Seni Rupa Murni Fakultas IImu Budaya Universitas Brawijaya, fatma@ub.ac.id, 085729898515) \\ Romy Setiawan ${ }^{2}$ \\ (Program Studi Seni Rupa Murni Fakultas IImu Budaya Universitas Brawijaya, romybelajar@ub.ac.id, 085649129796) \\ Dyanningrum Pradhikta ${ }^{3}$ \\ (Program Studi Seni Rupa Murni Fakultas IImu Budaya Universitas Brawijaya, ade.pradhikta@ub.ac.id, 081809627738)
}

\begin{abstract}
Lifestyle, especially fashion will follow its era, including batik. Without breakthroughs, batik innovation and creations will be increasingly abandoned. Therefore we need new breakthroughs that will make batik popular. The creation of batik based on ideas from dinosaurs is one form of development carried out. Therefore in this study an attempt was made to visualize the character of dinosaurs in the form of batik motifs. The research method used is the creation method in which there are three stages in the creation process, namely the initial stage / overall exploration, continued from the initial stage / specific exploration and realization. The results of this study are expected to make a positive contribution to the development of batik which is expected to synergize with the developing popular culture. Wahana Dino Park, is part of the popular culture that developed in the city of Batu. The popularity and uniqueness of Dino Park will inspire the creation of batik motifs. Batik is made in two choices of motifs, which overall show the character or figure of dinosaurs in Dino Park combined with a sprinkling of floral motifs found in the city of Batu.
\end{abstract}

Keywords: Keyword Popular Culture, Dinosaurs, Batik.

\section{ABSTRAK}

Gaya hidup terutama fashion akan mengikuti jamannya termasuk batik. Tanpa terobosan, inovasi dan kreasi batik akan semakin inggalkan. Oleh karena itu dibutuhkan terobosan-terobosan baru yang akan membuat batik populer. Penciptaan batik berdasarkan ide dari dinosaurus merupakan salah satu bentuk pengembangan yang dilakukan. Karenanya pada penelitian ini dilakukan upaya untuk memvisualisasikan karakter dinosaurus dalam bentuk motif batik. Metode penelitian yang digunakan adalah metode penciptaan dimana terdapat tiga tahap dalam proses penciptaan ini yaitu tahap awal/ekplorasi secara keseluruhan, lanjutan dari tahap awal/eksplorasi secara spesifik dan perwujudan. Hasil penelitian ini diharapkan dapat memberikan kontribusi positif bagi perkembangan batik yang diharapkan bersinergi dengan budaya popular yang sedang berkembang. Wahana Dino Park ,merupakan bagian dari budaya popular yang berkembang di kota Batu. Kepopuleran dan keunikan yang dimiliki Dino Park akan menjadi inspirasi penciptaan motif batik tulis. Batik dibuat dalam dua pilihan motif, dimana secara keseluruhan menampilkan karakter atau figur dinosaurus yang ada di Dino Park dipadu dengan taburan motif bunga yang terdapat di kota Batu.

Kata Kunci: Budaya Populer, Dinosaurus, Batik. 


\section{PENDAHULUAN}

Batik masih dipandang dengan sesuatu yang formal dan tradisi, didominasi dengan motif terkait relief, legenda dan kondisi alam. Hal itu menjauhkan batik dari kaum muda yang dihidupi oleh kebudayaan milenial. Berbagai upaya untuk melestarikan batik disesuaikan dengan perkembangan pasar. Mempopulerkan batik harus mampu bersinergi dengan kebudayaan hari ini. Kebudayaan popular selalu bersekutu dengan industri yang secara kasar berburu laba (Heryanto, 2012:6). Budaya popular seringkali dijuluki budaya massa (Strinati, 1995:10), istilah tersebut mengacu pada budaya yang direndahkan, diremehkan, dangkal, dibuat-buat, dan seragam (Strinarti, 1995:21). Batu merupakan salah satu kota yang dihidupi oleh budaya popular. Dengan beragaman latar belakang sosial budaya, munculnya kafe, distro, mall dan kehadiran destinasi wisata, menjadikan Malang perlahan tumbuh menjadi kota metropolitan. Merebaknya budaya popular di kota Batu ini memberikan peluang berkembangannya industri fashion (batik).

Gaya hidup terutama fashion di kota Batu akan mengikuti jamannya. Tanpa terobosan, inovasi dan kreasi batik akan semakin ditinggalkan. Barik kreasi mengandung kebaharuan, memiliki karakter khusus (unik), dan sesuai dengan perkembangan zaman yang ditandai oleh trend (Anas dalam Febrasari, 2019: 162). Batik harus mampu hadir dalam kebudayaan popular tersebut melalui terobosan baru. Salah satunya melalui penciptaan batik berdasarkan ide Dinosaurus, dimana melalui karakter dinosaurus ini batik dapat menjadi bagian dari budaya popular. Dinosaurus menjadi budaya dunia dan terus popular, menjadi topik di buku, film dan di berbagai media (Hady: 2017:99). Hal itu juga mensinergikan antara keberadaan Jatim Park 3 atau Dino Park yang berada di kota Batu. Jatim Park adalah salah satu destinasi wisata edukasi di kota Batu. Dino Park dipenuhi dengan karakter-karakter dinosaurus dan wahana lainnya. Karakter binatang prasejarah ini yang terdapat dalam Dino Park sangat beragam sesuai dengan zaman perkembangbiakannya, antara lain, triceratops, terano saurus, mammoth, semilodon, dan lain sebagainya.

Dalam penciptaan batik yang terinspirasi dari karakter dinosaurus akan diwujudkan menjadi batik kontemporer. Dimana karakter dinosaurus yang terdapat dalam destinasi wisata Dino Park akan menjadi inspirasi dalam penciptaan motif batik ini. Melalui penciptaan ini diharapkan bisa sebagai referensi baru dalam menciptakan produk batik yang ide dasarnya dari destinasi wisata yang ada di kota Batu, sekaligus merupakan salah satu cara mensinergikan tradisi batik dengan kebudayaan hari ini. Selain menampilkan karakter-karakter dinosaurus batik yang akan diciptakan akan menggunakan warna-warna yang beragam (lebih dari 2 warna), sehingga batik ini lebih menarik, unik dan bisa dipakai oleh berbagai kalangan, sebagaimana identitas dalam budaya populer.

\section{LANDASAN TEORI}

Kebudayaan popular menawarkan keinginan yang lebih bagi masyarakat untuk mendapatkan hal-hal yang sifatnya instan dan menarik terutama berkaitan dengan hal memenuhi hasrat hari ini. Media massa menjadi salah satu alat yang sangat ampuh dijadikan perantara/alat untuk menarik keinginan masyarakat dengan hasrat untuk terus membeli. Menjadi konsumtif merupakan salah satu ciri yang ditimbulkan oleh pengaruh kebudayaan popular, masyarakat di buat terbius, terbuai oleh 
iklan-iklan yang disajikan, menjadi hedonis dan melahirkan kesadaran palsu. Budaya pop sering disebut budaya massa yang ditopang oleh industri, semua di komodifikasi untuk kebutuhan konsumsi. Sehingga terlahirlah sebuah wajah masyarakat baru:"masyarakat komoditas" yang membiarkan kebudayaan pop dan memaksakan penyembahan, pemujaan, pengkultusan, ecstasy gaya hidup (Ibrahim, 1997:12).

Perkembangan budaya merupakan salah satu munculnya pemahaman baru dalam melihat realita yang ada, begitu juga dengan perkembangan budaya yang dihasilkan termasuk batik. Angela Oscario (2014: 552) dalam penelitiannya yang berjudul "Simulasi Citra Nasionalis Melalui Fashion: Studi Kasus Batik Printing Dalam Gaya Hidup Post Modern Masyarakat Kota" menjelaskan bahwa Gempuran batik printing, terutama batik printing impor mengancam eksistensi batik tulis maupun cap Indonesia. Hal ini disinyalir terjadi karena di tengah masyarakat Jakarta yang kehilangan identitas karena ikatan dengan daerah asal telah memudar, batik printing justru mampu memberikan identitas - yang sebenarnya artifisial - bagi masyarakat Jakarta dengan cara mensimulasikan citra nasionalis. Citra menjadi sangat dominan dan menentukan realitas yang sesungguhnya hanya merupakan ilusi atau tak nyata. Masyarakat Jakarta hanya mementingkan tampilan permukaan dan gaya dan telah lebur menjadi satu konsumsi masif. Sedangkan Danis Agung Gunawan (2013) dalam penelitiannya yang berjudul "Kajian "Batik Bola" Dalam Arus Budaya Populer Dengan Pendekatan Cultural Studies" menjelaskan munculnya batik bola di Surakarta dilatar belakangi oleh sosial budaya masyarakat Surakarta sebagai sentral batik dan pecinta bola serta melalui ide-ide yang menarik dan dilatar belakangi keterampilan yang dimiliki merupakan ide awal terciptanya batik bermotif bola di Surakarta. Ketertarikan masyarakat akan produk batik bola dapat dilihat dari keunikan produk tersebut, adanya unsur tradisi berpadu dengan suatu hal yang populer menjadikannya produk baru yang belum pernah ada. Peran media menjadikan batik bola makin dikenal dan selanjutnya menjadi barang trend. Hal tersebut juga menjadi faktor ketertarikan masyarakat terhadap batik bola, produk dari budaya massa mempengaruhi audiens

Sebagai referensi visual batik Dinosaurus, salah satunya adalah Thebatik. Thebatik merupakan rumah produksi batik, batik motif dinosaurus yang diciptakan merupakan batik cap dengan komposisi motif beraturan pada bidang kain. Secara pewarnaan Thebatik menggunakan warna gradasi, dan serta setiap karakter dinosaurus yang dibuat memiliki warna yang bersamaa. Penciptaan batik dinosaurus yang penulis buat terinspirasi dari batik dinosaursnya Thebatik, tetapi batik yang akan penulis ciptakan lebih menampilkan karakter dinosaurus yang beragan atau lebih dari satu karakter, dimana karakter dinosaurus tersebut terinpirasi dari objek wisata Jatim Park 3 yang berada di daerah Batu. Dari segi pewarnaan yang akan dibuat juga terdiri dari dua warna lebih dengan teknik colet dan celup.

\section{METODE}

Metode yang digunakan dalam penelitian ini adalah metode penciptaan seni rupa berdasarkan L.H Chapman yang terdiri atas tiga tahapan yaitu (Chapman dalam Setiawan, 2018):

1)Tahap pertama, upaya menemukan gagasan.

Gagasan dan ide merupakan awal bagi seseorang dalam mencipta. Ide dalam penciptaan ini berasal dari budaya popular yang sedang berkembang pada saat ini di Jawa Timur 
khususnya daerah Batu. Batu merupakan salah satu destinasi wisata yang banyak dikunjungi oleh wisatawan Asing atau Lokal. Detinasi wisata diderah Batu beragam, dari keindahan alaman yang ditata sedemikian rupa sampai wisata buatan yang dikemas apik seolah-olah nyata atau hidup seperti aslinya. Destinasi wisata buatan termasuk terluas dan terbanyak di daerah Batu, bahkan termasuk salah satu destinasi wisata yang diminati masyarakat Indonesia. Tempat-tempat wisata buatan dikota Batu seperti Jatim Park Satu, Jatim Park Dua, Jatim Park Tiga, BNS, Predator Park dan lain-lain. Bentuk wisata buatan ini berkembang pesat, pengunjung seolah-olah dekat tanpa berjarak dari setiap momen yang di hadirkan tempat wisata. Berkembangnya parawisata kota Batu secara tidak langsung bedampak pada perkembangan budaya masyarakatnya. Tidak hanya tempat wisata, tempat - tempat berkumpul atau hanya sekedar bersantai bersama teman atau keluarga disajikan dengan apik oleh kota ini. Berjamuran cafe-cafe disekitaran Batu dengan tampilan-tampilan yang menarik hasil kreasi tangan-tangan terampil. Hal ini dengan sengaja dirancang dan disajikan bagi pengunjung yang datang.

Ide dalam penciptaan ini berasal dari destinasi wisata Dino Park atau Jatim Park 3. Selain menjadi tempat wisata yang menyenangkan, Dino Park juga merupakan destinasi wisata edukasi. Pemilihan Dino Park sebagai ide dalam penciptaan ini juga didasari apa yang disajikan Dino Park bagi pengunjungnya. Secara garis besar Dino Park dikenal sebagai miniature taman Dinosaurus. Dinosaurus merupakan karakter binatang yang hampir dikenal dari kalangan anak-anak sampai dewasa. Dino Park menghadirkam beberapa karakter dinosaurus lengkap dengan edukasi yang ditampilkan secara menarik, seolah-olah ini nyata bahkan dekat dari kita tanpa berjarak. Dino Park menghapus batas antara pengunjung dan karakter yang dihadirkan. Selain itu kehadiran Dino Park sudah menjadi bagian terpenting masyarakat Batu, terlihat dari berkembangnya secara pesat budaya ini. Kehadiran Dino Park tentunya ditopang oleh industri yang sudah mapan, sehingga mempromosikan hal ini kemasyarakat menjadi hal yang tidak terlalu sulit. Beberapa figur dinosaurus yang sudah dikenal masyarakat seperti Theceratop, Brontosaurus/Apatosaurus dan Tirek, menjadi ikon karakter yang di pajang pada beberapa tempat strategis. Karakter ini merupakan figur dinosaurus yang paling banyak dikenal masyarakat Figur dinosaurus ditampilkan seolah-olah hidup, lengkap dengan suara yang dikeluarkan serta bisa bergerak. Tidak hanya figur dino yang menarik, penempatan dino yang seolah-olah di alam bebas atau hutan membuat objek wisata ini menarik untuk dikunjungi (seolah nyata).

2)Tahap kedua, adalah melakukan penyempurnaan dari ide atau gagasan yang sudah didapat.

Melalui brainstorming dan pengamatan langsung ke Jatim Park 3 atau Dino Park terdapat beberapa karakter yang menjadi ikon tempat ini yaitu Brontosaurus/Apatosaurus, Triceratop dan Tirek. Apabila dikelompokkan karakter dinosurus yang berada di Jatim Park 3 bisa dibagi menjadi dua yaitu kelompok pemakan daging, pemakan tumbuhan dan daging dan pemakan tumbuhan. Dalam penciptaan batik ini konsep yang dikembangkan tentang karakter dinosaurus pemakan tumbuhan. Bentuk yang dihadirkan menjadi motif batik adalah secara stilasi sehingga karakter-karakter dino yang tanguh bisa terlihat indah dan menarik setelah 
digoreskan menggunakan malam dan warna diatas kain.

3)Tahap ketiga, adalah visualisasi ke dalam medium atau perwujudan

Pada tahap ini merupakan proses pernciptaan pada media yang sudah ditentukan dalam hal ini adalah ekperimen pembuatan batik dengan inspirasi karakter dinosaurus (Jatim Park 3). Setelah dilakukan pemilihan motif yang akan dibuat, pada tahap ini dimulai dengan proses pemindahan pola atau motif pada kain (pola yang akan dipindahkan sudah berukuran 1:1 dengan besar bahan yang akan dibatik). Setelah itu dilakukan pembatikan atau pencantingan malam pada kain dengan mengikuti motif yang sudah ada. Pada tahap selanjutnya proses pewarnaan, dilakukan dengan cara di colek dan dicelup. Setelah proses pewarnaan selesai selanjutnya dilakukan proses pelorotan malam dari kain. Ini dilakukan dengan cara merebus kain dalam panci berisi air panas, dengan tujuan kain betul-betul bersih dari malam.

\section{HASIL DAN PEMBAHASAN}

Kota Batu terkenal memiliki tempat wisata yang cukup populer. Jawa Timur Park Grup menawarkan konsep wisata edukasi dengan tema Prasejarah, dengan mengambil nama Dino Park menjadi wahana satu-satunya di Kota Batu sekaligus terbesar dan terlengkap dalam menyajikan berbagai wahan bertema Dinosaurus. Di lokasi seluas 6,5 hektar, Dino Park diisi dengan berbagai spesies Dinosaurus raksasa yang bisa memberikan wisata edukasi lebih dekat tentang nama, spesies, makanan, habitat dan sekaligus sebagai wisata hiburan. Replika yang ditampilkan adalah Dinosaurus herbivora (pemakan tumbuhan), Dinosaurus karnivora (pemakan daging), dan juga Dinosaurus omnivora (pemakan tumbuhan dan daging). Diantara cukup banyak Dinosaurus disana yang cukup populer diantaranya Tyranosaurusrex, Brontosaurus/ Apatosaurus si leher panjang, Triceratops, Dinosaurus terbang Pterodactyl dan gajah zaman es Mamoth.

Triceratops dengan nama panggilan pendeknya Tritop, dikenal sebagai Dinosaurus yang melindungi diri dengan tanduknya yang tajam. Triceratops memiliki tiga tanduk, dua di alisnya dan satu di hidungnya. Beberapa ahli mengatakan Triceratops tidak bisa berlari dan menggunakan tanduknya yang tajam untuk berkomunikasi. Triceratops disebut sebagai Dinosaurus ksatria, karena bentuk kombinasi kepala dan tanduknya membuat dirinya seperti ksatria dengan pedang dan tameng. Triceratops dalah dinosaurus herbivora, artinya la pemakan tumbuhan. Sedangkan Brontosaurus atau juga dikenal dengan nama Apatosaurus adalah hewan besar, berkaki empat dengan ekor panjang seperti cambuk, dan kaki depan yang sedikit lebih pendek dari anggota belakangnya. Brontosaurus memiliki leher yang panjang, kurus dan kepala kecil yang disesuaikan dengan gaya hidup herbivora. Brontosaurus sering muncul sebagai sinonim untuk Dinosaurus itu sendiri, hal ini juga terlihat dari banyaknya Brontosaurus ditampilkan diberbagai media baik visual maupun audio visual, seperti kemasan makanan anak dan film.

Brontosaurus dan Triceratops merupakan spesies Dinosaurus yang tergolong paling populer di kalangan anak-anak khususnya, selain Tyrex pemakan daging. Brontosaurus dan Triceratops sangat melekat tidak hanya dalam wujud visualnya tetapi juga karakteristiknya. Karakter kedua spesies tersebut sebagai Dinosaurus baik, ramah, dan setia kawan. Meskipun termasuk Dinosaurus pemakan tumbuhan dan tidak mempunyai kekuatan 
layaknya Dinosaurus pemangsa, namun karena hidup berkelompok menjadikan mereka kuat. Hal ini menjadi alasan kuat memilih Brontosaurus dan Triceratops untuk dijadikan motif Batik, selain pertimbangan estetis dan estetik batik motif dino ini, yaitu estetika desain motif batik itu sendiri dan pemaknaan hasil jadi pakai motif batik dino. Penciptaan motif batik ini sendiri dipilih agar batik tetap menjadi populer ditengah menurunnya kecintaan generasi saat ini dengan produk tradisional.

Penciptaan motif batik Dinosaurus ini merupakan alternatif produk batik yang mengusung tema kontemporer. Gambar di bawah ini merupakan kreasi karakter Dinosaurus yang sesuai dan relevan untuk dijadikan motif batik. Terdapat dua desain alternatif motif batik berdasarkan karakter Dinosaurus. Keseluruhan merupakan hasil rekonstruksi Dinosaurus menjadi bentuk visual motif batik. Penyederhanaan karakter Dinosaurus menjadi kunci utama dalam proses penciptaan motif batik, selain ornamen pendukungnya. Brontosaurus dan Triceratops menjadi ide penciptaan motif utama dengan isen-isen tumbuhan bunga yang merepresentasikan Kota Batu. Bunga khas Kota Batu dipilih sebagai isenisen secara sederhana menunjukkan keindahaan alam dan sumber daya alam yang indah. Makna lain dari isen-isen bunga adalah makna harapan akan keselamatan dan kebahagian.

Gambar 1 menampilkan karakter Brontosaurus pada motifnya, sekaligus menjadi motif utama yang divisualisasikan berulang. Menggunakan motif tumpal yang terdiri atas perpaduan garis dan titik, menghasilkan sebuah desain motif batik yang menarik dan unik, karena secara sekilas tidak terlihat bahwa batik tersebut menggunakan motif Brontosaurus. Isen-isen pada motif ini adalah berupa bunga empat kelopak dan perpaduan garis serta titik. Warna yang digunakan pada motif ini adalah warna tunggal yaitu coklat. Warna cokelat melambangkan ketenangan dan keseimbangan. Selain warna coklat motif batik Dinosaurus ini juga dirancang menggunakan warna tunggal merah yang melambangkan keberanian dan kasih sayang.

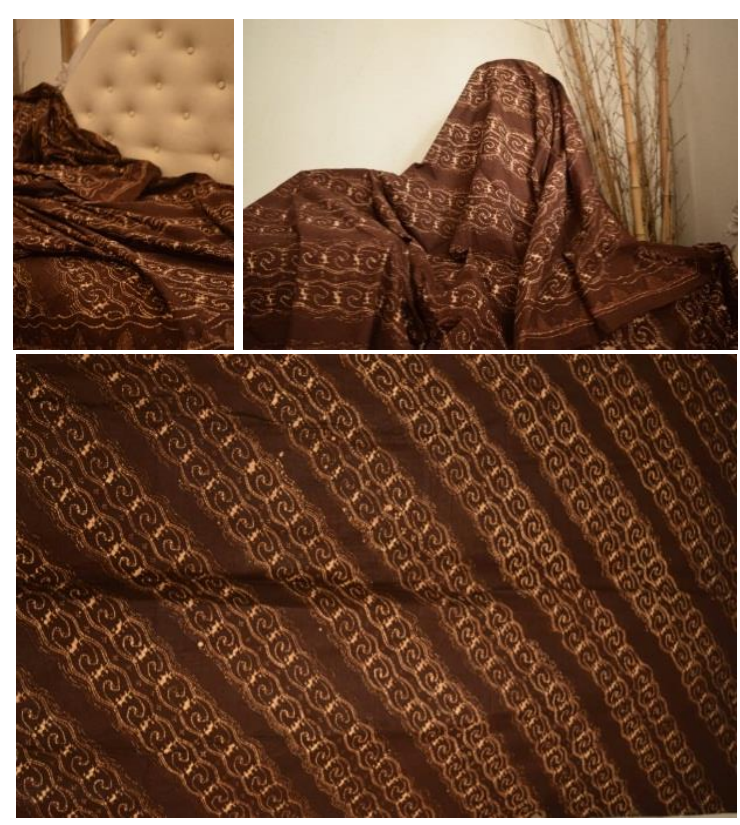

Gambar 1. Batik Motif Dinosaurus dengan Warna Coklat

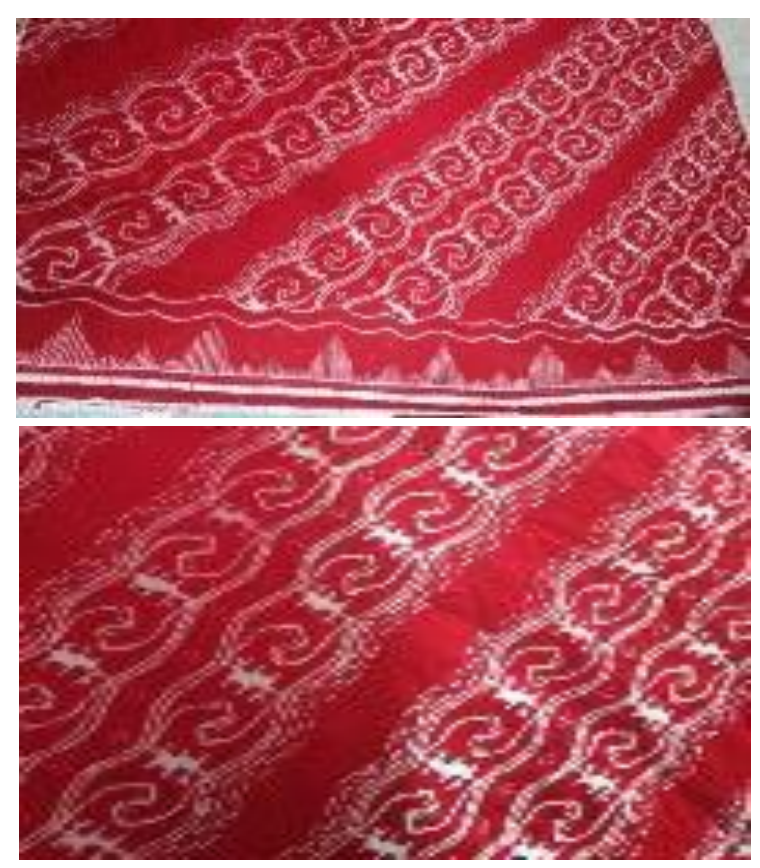

Gambar 2. Batik Motif Dinosaurus dengan Warna Merah 
Selain menampilkan karakter-karakter dinosaurus batik yang diciptakan ada yang menggunakan warna-warna yang beragam (2 warna), sehingga batik ini lebih menarik dan unik. Meskipun tidak menutup kemungkinan warna tersebut bisa dikembangkan dan dieksplorasi lagi. Seperti pada gambar 3 menampilkan karakter Brontosaurus dan Triceratops pada motifnya, sekaligus menjadi motif utama yang divisualisasikan berulang. Menggunakan motif tumpal yang terdiri atas isen-isen bunga, menghasilkan sebuah desain motif batik yang menarik dan unik baik dari segi konsep maupun visualnya. Isen-isen pada motif ini adalah berupa bunga dan daun yang diambil dari tanaman yang tumbuh di daerah kota Batu. Warna yang digunakan pada motif ini adalah warna kuning dan biru. Warna kuning melambangkan kejayaan, keagungan, kecerdasan dan keabadian, sedangkan warna biru melambangkan percaya diri, kesetiaan dan warna yang memiliki efek positif.
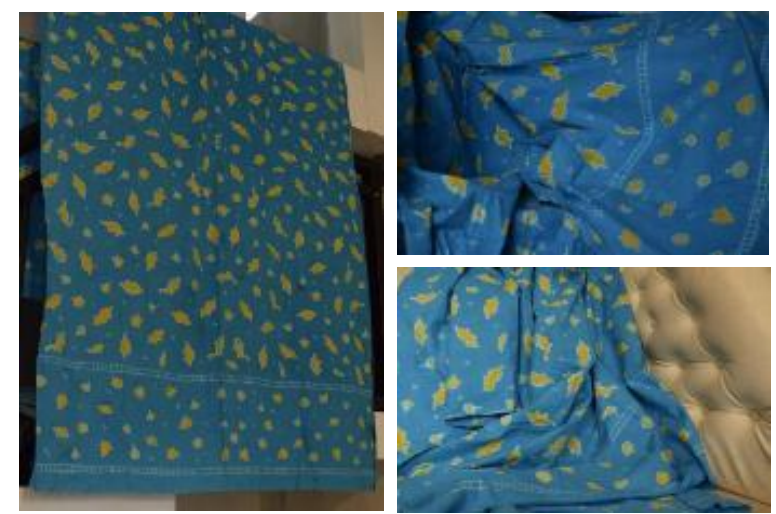

Gambar 3. Batik Motif Dinosaurus 2 dengan Warna Biru dan Kuning

Motif Batik Dinosaurus di atas juga diaplikasikan pada warna hitam dan kuning seperti pada gambar 4. Warna kuning melambangkan kejayaan, keagungan, kecerdasan dan keabadian, sedangkan warna hitam melambangkan keagungan dan percaya diri.

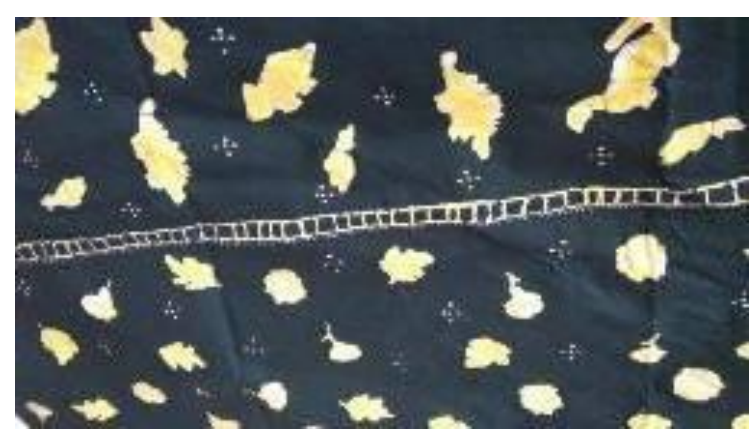

Gambar 4. Batik Motif Dinosaurus 2 dengan Warna Hitam dan Kuning

\section{PENUTUP}

Berangkat dari ide tentang budaya popular yang sedang berkembang di Batu sebagai kota dengan banyak pilihan destinasi wisata. Berkembangnya pariwisata kota Batu secara tidak langsung bedampak pada perkembangan budaya masyarakatnya. Melalui penciptaan batik sebagai perwujudan penciptaan karya penelitian ini, diharapkan tetap dapat melestarikan warisan budaya Nusantara yang ditampilkan dalam produk budaya popular. Perwujudan karakter dinosaurus sebagai alternatif ide penciptaan batik tulis menghasilkan batik yang menarik dan unik baik dari segi konsep maupun visualnya.

Pembuatan desain motif batik berdasarkan karakter Dinosaurus ini merupakan salah satu bentuk kreasi yang dilakukan sebagai wujud batik bagian dari batik populer. Sebagaimana identitas dalam budaya popular, diharapkan produk penciptaan ini menjadi merchandise destinasi wisata Dino Park Batu. Sehingga melalui kreasi batik bukan hanya Dino Park saja yang dikenal masyarakat, tetapi batik yang menarik, unik dan bisa dipakai oleh berbagai kalangan sebagai identitas dalam budaya populer. 


\section{Daftar Pustaka}

Febrasari, Andina, dkk. 2018. "Batik Tulis Padang Lamun (Padang Lamun sebagai Sumber Ide Perancangan Batik Tulis untuk Selendang Sutra)" dalam jurnal Corak: Jurnal Seni Kriya Vol 7 No. 22018

Gunawan. Danis Agung. 2014. Kajian "Batik Bola" Dalam Arus Budaya Populer Dengan Pendekatan Cultural Studies. Surakarta: Skripsi

Hady, Ahmad Prasetya. 2017. "Stilasi Hewan Prasejarah dalam Bentuk Senjata Kapak" dalam jurnal Corak: Jurnal Seni Kriya Vol 6 No. 22017

Ibrahim, Subandy Idi. 1997. Ecstasy Gaya Hidup. Bandung: Mizan

Oscario, Angela. 2014. "Simulasi Citra Nasionalis Melalui Fashion: Studi Kasus Batik Printing Dalam Gaya Hidup Post Modern Masyarakat Kota" dalam Jurnal Humaniora Vol 5 No.2 2014

Setiawan, Romy. 2015. Visualisasi Karakter Kinara Kinari Pada Relief Candi Badut Sebagai Inovasi Penciptaan Motif Batik. Malang: Tidak diterbitkan. 